\title{
Mid-short-term risk assessment of power systems considering impact of external environment
}

\author{
Ning ZHANG, Chongqing KANG ( $\bowtie)$, \\ Jingkun LIU, Jianbo XIN, Junbiao WAN, \\ Jing HU, Wenxiao WEI
}

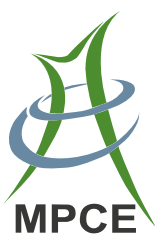

\begin{abstract}
Ice flashover, lightning flashover and bird damage are the main reasons that cause transmission facility failure. The impact of these environmental factors on the operational risk levels of power systems should be taken into account in power system maintenance scheduling and operation planning. This paper studies the midshort-term risk assessment methodology considering the impact of the external environment. The relationship model between natural disasters and transmission lines is presented. The conditional outage rate model and the sampling technique are then proposed considering the correlated outage of multiple transmission lines when a disaster happens. The framework of the mid-short-term risk assessment model is outlined. A test case of Jiangxi provincial power grid validates the proposed model. The results show that the model can quantify the impact of disasters on the forced outage rate of transmission component and their outage correlation, and thus effectively revealing the mid-short-term risk of power systems. The model can facilitate a more strategic decision-making on maintenance scheduling and operation planning of power systems.
\end{abstract}

Received: 15 July 2013/Accepted: 5 August 2013 / Published online: 12 September 2013

(C) The Author(s) 2013. This article is published with open access at Springerlink.com

N. ZHANG, C. KANG, J. LIU, State Key Laboratory of Power

Systems, Department of Electrical Engineering, Tsinghua

University, Beijing 100084, China

$(\bowtie)$ e-mail: cqkang@tsinghua.edu.cn

N. ZHANG

e-mail: ningzhang@mail.tsinghua.edu.cn

J. LIU

e-mail: Liu_j_kk@163.com

J. XIN, J. WAN, J. HU, Jiangxi Electric Power Research Institute, Nanchang 330096, China

W. WEI, School of Electrical Engineering and Automation,

Harbin Institute of Technology, Harbin 150001, China
Keywords Mid-short-term risk assessment, External environment, Natural disasters, Outage correlation, Conditional outage probability

\section{Introduction}

As the increasing scale of power systems and the growing reliance of human society on electricity, the losses of the power system blackout become larger than ever before. The capability of power system that could serve the load securely and reliably is attracting more and more attentions. Based on the theory of risk assessment in the power system planning studies, the theory and the methodology of operational risk assessment of power systems have been proposed [1]. The operational risk assessment quantifies the mid-short-term or even real-time risk level of power systems according to the status and external environment of the generation and transmission facilities. The results of operational risk assessment can help the power system operator make wise dispatching decisions. The operational risk assessment acts as an important role in the power system to avoid the large scale blackout.

Previous researches show that the external environment of the transmission facilities has a significant impact on the forced outage rate (FOR) [2, 3]. In the time horizon of operational risk assessment the detailed information of the component external environment is much more certain compared with long-term risk assessment. Therefore, the operational risk assessment should use the specified FOR of the transmission component under certain condition, rather than using the long-term average value [4]. In recent years, there are several power system blackouts around the world that are caused by natural disasters, such as ice storm, lightning storm and bird migration [5-7]. Considering the impact of these disasters is crucial for revealing the operational risk level of the power system. 
The issue of the operational risk assessment has attracted much attention. Many studies focus on modeling the shortterm FOR of the component. Fuzzy models and probabilistic models are mainly used to build a relationship between the FOR of the component and its operational status or external environment. Reference [8] proposed a fuzzy clustering and similarity based model in the risk analysis under the ice storm. Reference [9] outlined a time-varying and condition-based Markov process model for the outage of transmission components. References [10, 11] proposed a weather dependent short-term reliability model for the transmission equipment while Ref. [12] proposed a current dependent model. Reference [13] built an outage probability model for transmission lines that can consider multiple kinds of disasters. Reference [14] used Pareto distribution and Copula function to model the joint probability distribution for ice and wind loads on transmission lines and towers. A series of methods have been proposed for evaluating operational risk. Random fuzzy sampling method is proposed in [15] while a credibility theory based risk assessment method is proposed in [16]. Reference [17] evaluated the power system risk under the hurricane by dividing the power system into different regions according to the path of hurricane. The fuzzy inference system is used to build the nonlinear relationship between hurricane parameters and the increment of the component outage rates. Reference [18] built up an analytical function between the effective wind speed of typhoon and the FOR of transmission lines and proposes a risk evaluation model that considers the transient stability. Reference [19] discussed the impact of real-time FOR of transmission lines on the results of operational reliability evaluation.

All of the researches above only consider the impact of operational conditions on each single component of power system and do not take into account the coupling of outages between multiple components. In fact, under the condition of extreme weather or disasters, the outages of the facilities affected would have a strong correlation [20]. This paper proposes a mid-short-term risk assessment model considering the impact of external environment on transmission lines. Firstly, the features of the mid-short-term risk assessment model are compared with those of long-term and real-time risk assessment models. Secondly, the relationship model between natural disasters and transmission lines is presented. The conditional outage rate model and the sampling technique are proposed, which consider the correlated outage of multiple transmission lines when a disaster happens. Finally, the framework of the mid-short-term risk assessment model is outlined.

\section{Features of mid-short-term risk assessment model}

The mid-short-term risk assessment model in this paper can provide auxiliary information for maintenance scheduling and operational planning of power systems. The time scale of the risk assessment model ranges in the middle of the long-term and real-time risk assessment. The power system risk assessments on these three time scales are different in terms of modeling, factors considered and application areas. Table 1 compares the differences among the long-term, mid-shortterm and real-time risk assessment methods based on [11].

Both the mid-short-term and real-time risk assessments belong to the field of operational risk assessment. The main difference is that the real-time parameters, such as environmental temperature, wind speed, sunshine heat, and load level cannot be obtained in several days or weeks ahead of time. Therefore, the temperature dependent or current dependent models can hardly be incorporated into the mid-short-term risk assessment model. However, on such time horizon the probability of harmful disasters, such as ice storm, lightning storm and bird migration could be forecasted, since these disasters have strong seasonal regularities. These disasters should be considered in the risk assessment because they are the main reasons of the transmission facility failure. Furthermore, the healthiness of the transmission component can also be considered in the mid-short-term risk assessment. The rest of the paper will focus on the conditional outage rate modeling and the sampling technique for transmission lines under disasters.

\section{Transmission line reliability model considering disaster impact}

\subsection{Relationship model between transmission lines and disasters}

In the real-world power system, the geographical relationship between the paths of the transmission lines and the disasters may be complex [17]. Some lines are not located entirely in one disaster area. Some may go through multiple disaster areas. At the same time, there are usually more than one line located in one disaster area. The relationship model between the transmission lines and the disasters is outlined in order to mathematically describe such relationship. The principle of the model is illustrated in Fig. 1. The disaster area model is built according to the surveying map of disasters. The principles of forming the disaster areas include:

1) Adjacent regions that are influenced by the same disaster should be gathered as one disaster area. One disaster area only corresponds to one single kind of disaster, while one kind of disaster can be divided into multiple areas.

2) The occurrence of the disaster in one area should have consistency. If two regions may not have disasters 
Table 1 Comparison of the risk assessment methods among different time scales

\begin{tabular}{llllll}
\hline Type & $\begin{array}{c}\text { Time } \\
\text { horizon }\end{array}$ & Application & Operational condition & $\begin{array}{c}\text { Component } \\
\text { outage } \\
\text { model }\end{array}$ & $\begin{array}{l}\text { Meaning of component } \\
\text { reliability model }\end{array}$ \\
\hline $\begin{array}{c}\text { Long-term } \\
\text { risk } \\
\text { assessment }\end{array}$ & $\begin{array}{c}1 \text { year to } \\
\text { several } \\
\text { years }\end{array}$ & $\begin{array}{c}\text { Generation and } \\
\text { transmission } \\
\text { expansion } \\
\text { planning }\end{array}$ & Do not consider any operation condition & $\begin{array}{c}\text { Reparable } \\
\text { failure }\end{array}$ & $\begin{array}{c}\text { The ratio of time that the } \\
\text { component is not available }\end{array}$ \\
$\begin{array}{c}\text { Mid-short- } \\
\text { term risk } \\
\text { assessment }\end{array}$ & $\begin{array}{c}\text { Several } \\
\text { days to } \\
\text { several } \\
\text { weeks }\end{array}$ & $\begin{array}{c}\text { Maintenance } \\
\text { scheduling and } \\
\text { operation } \\
\text { planning }\end{array}$ & $\begin{array}{c}\text { Natural disasters and healthiness of the } \\
\text { component }\end{array}$ & $\begin{array}{c}\text { Irreparable } \\
\text { failure }\end{array}$ & $\begin{array}{c}\text { The probability that the } \\
\text { components break down in } \\
\text { the time horizon }\end{array}$ \\
$\begin{array}{c}\text { Real-time } \\
\text { risk } \\
\text { assessment }\end{array}$ & $\begin{array}{c}\text { Minutes to } \\
\text { hours }\end{array}$ & $\begin{array}{c}\text { Day-ahead } \\
\text { scheduling and } \\
\text { real-time } \\
\text { dispatching }\end{array}$ & $\begin{array}{c}\text { Environmental temperature, wind speed, } \\
\text { sunshine heat, load level, service time, } \\
\text { state monitoring indicators }\end{array}$ & $\begin{array}{c}\text { Irreparable } \\
\text { failure }\end{array}$ & $\begin{array}{c}\text { The probability that the } \\
\text { components break down in } \\
\text { the time horizon }\end{array}$ \\
\hline
\end{tabular}

occurred at the same time, they should be divided into two separate areas.

3) A disaster area may cover multiple regions that are not connected geographically.

The relationship model between the transmission lines and the disaster areas is then built using geographic information system (GIS). Each transmission line is split into segments according to the disaster areas it passes by. In Fig. 1, Line 3 passes all the three disaster areas and therefore should be split into 7 segments. Segment 1, 3, 5, 7 are not located in any disaster area and can be combined into one segment since their reliability models are identical. Assuming that Line $i$ passes through $k_{i}$ disaster areas, the line should be divided into $k_{i}+1$ segments and is marked as $i_{j}, j=1,2, \ldots, k_{i}+1$. Segment $i_{k_{i}+1}$ represents

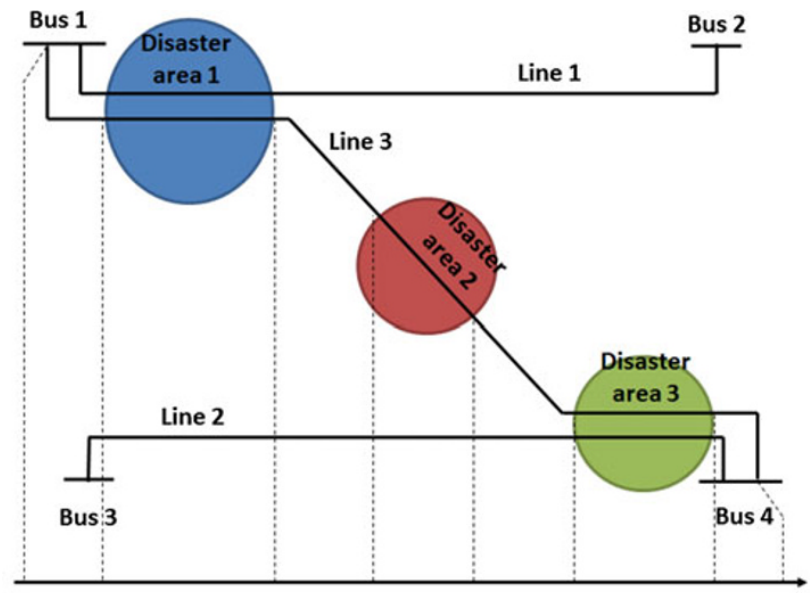

Segment 1 Segment 2 Segment 3 Segment 4 Segment 5 Segment 6 Segment 7

Fig. 1 Illustration of the relationship between disasters and transmission lines the segment that do not locate in any disaster area. Assuming that there are totally $M$ disaster areas, Formula $i_{j} \in m$ means that the $j$-th segment of the $i$-th line locates in the $m$-th disaster area.

The method above provides a standard way for modeling the relationship between the transmission lines and the disasters. It should be noted that the proposed model do not consider the condition that multiple disaster areas may geographically overlap with each other. Indeed, some areas may involve multiple disasters, however, these disasters hardly happen together. Therefore, for each specific period of time in the risk assessment the disaster areas could be regarded as separated with each other.

\subsection{Conditional forced outage probability of transmission lines considering disaster impact}

The disaster-dependent random failure model for transmission lines is built based on the two-state weather model [10]. For a disaster area $m$, assuming that $P_{m}$ is the ratio of days that disasters happen through the whole year. For each line $i \in m$, assuming that $F_{i, m}$ is the ratio of tripout events caused by disaster area $m$ over all of the trip-out events and $\lambda_{i}$ is its overall trip-out rate. The conditional trip-out rate of the $i$-th line considering the disaster is

$\lambda_{i, m}= \begin{cases}\lambda_{i} \frac{F_{i, m}}{P_{m}}, & \text { when disaster happens } \\ \lambda_{i} \frac{1-F_{i, m}}{1-P_{m}}, & \text { when disaster does not happen }\end{cases}$

The outage of the transmission line is regarded as an irreparable failure in the mid-short-term risk assessment. Assuming that $T$ is the start time period and $t$ is the time length of the risk assessment, the length of the $j$-th segment of the $i$-th line is $l_{i, j}$, the reclosing success probability of the line is $\eta_{i}$, the forced outage probability of the $j$-th segment of the $i$-th line from $T$ to $T+t$ can be calculated by 
$p_{i, j}=\frac{\int_{T}^{T+t}\left(1-\eta_{i}\right) \lambda_{i, m} l_{i, j} \mathrm{e}^{-\left(1-\eta_{i}\right) \lambda_{i, m} l_{i, j} t} \mathrm{~d} t}{\int_{T}^{\infty}\left(1-\eta_{i}\right) \lambda_{i, m} l_{i, j} \mathrm{e}^{-\left(1-\eta_{i}\right) \lambda_{i, m} l_{i, j} t} \mathrm{~d} t}=1-\mathrm{e}^{-\left(1-\eta_{i}\right) \lambda_{i, m} l_{i, j} t}$.

The model mentioned above can be explained using Fig. 2. The Zone 1 represents the probability space that the disaster happens while the Zone 2 represents the probability space that the disaster does not happen. The grey ellipse represents the probability space that the line is at the outage state, which locates partially in Zone 1 and partially in Zone 2 . When the disaster happens, the conditional forced outage probability is determined by the area proportion of Zone 3 out of Zone 1, otherwise it corresponds to the proportion of Zone 4 out of Zone 2 .

Using (1) and (2) the conditional forced outage probability of each segment for each line can be obtained when the state of each disaster area is available. Practically, the estimation of $F_{i, m}, \lambda_{i}$ and $\eta_{i}$ may be difficult in terms of lacking enough samples, since the trip-out is a small probability event. These parameters could be estimated by categories of voltage levels, assuming that the lines in the same categories have a similar reliability parameter.

\subsection{Sampling method considering outage correlation}

Once the disaster happens, it is more likely that the multiple segments of different lines in one disaster area have the outage simultaneously, which makes the outage occasions of different lines have positive correlation. A real example is the ice storm in Southern China in 2008. There are occasions that multiple transmission lines in one disaster area trip-off or fall out together in a short period of time. The correlation of the outages should be considered in the line state sampling.

Assuming that $L_{m}=\left|\left\{i_{j} \mid i_{j} \in m\right\}\right|$ is the number of segments located in the disaster area $m$ and outage correlation coefficient matrix among all the segments is $\boldsymbol{C}_{m} . \boldsymbol{C}_{m}$ can be decomposed into the product of a lower triangular

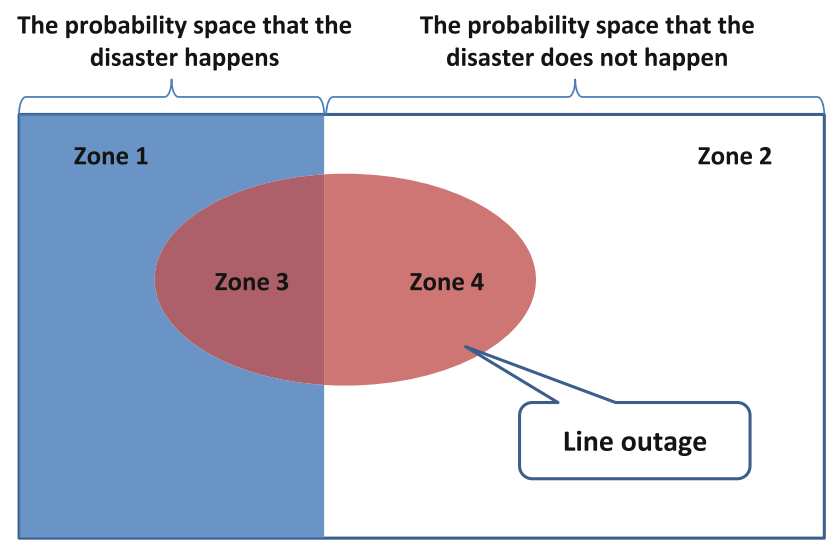

Fig. 2 Principles of calculating the conditional outage rate of the lines considering the natural disaster matrix and its transposed matrix using Cholesky decomposition method:

$\boldsymbol{C}_{i}=\boldsymbol{L} \boldsymbol{L}^{\mathrm{T}}$.

Generating a series of random numbers $\delta_{l}, \quad l=$ $1,2, \ldots, L_{m}$ to form a random vector $\Delta$ and transforming $\boldsymbol{\Delta}$ using $\boldsymbol{L}$, we have

$\tilde{\Delta}=\boldsymbol{L} \Delta$.

It can be proved that the elements in the random vector $\tilde{\Delta}$ has a multi-dimensional normal distribution with a correlation coefficient of $\boldsymbol{C}_{m}$ and the margin distribution of each element is still a standard normal distribution [21]. Assuming that the segment $i_{j}$ corresponds to the $l$-th element of $\tilde{\Delta}$, the state of segment $i_{j}$ is determined by:

$S_{i, j}=\left\{\begin{array}{ll}0, & \Phi\left(\tilde{\delta}_{l}\right) \leq p_{i, j} \\ 1, & \Phi\left(\tilde{\delta}_{l}\right)>p_{i, j}\end{array}\right.$,

where $\Phi(\cdot)$ is the standard normal distribution function. Using (5), the correlation of all the segments in a disaster area would exist in their sampled states.

In fact, $\Phi\left(\tilde{\delta}_{1}\right), \Phi\left(\tilde{\delta}_{2}\right), \ldots, \Phi\left(\tilde{\delta}_{L_{m}}\right)$ obtained from the method above is the sampling of the Gaussian Copula function with a correlation coefficient matrix of $\boldsymbol{C}_{m}$. The Copula function is a kind of special distribution function which has a uniform marginal distribution on each dimension. Copula functions are mainly used in modeling the correlation between stochastic variables. Specifically, the Gaussian Copula function models the dependency among multiple Gaussian distributed variables. The advantage of the Copula function is that each marginal distribution of a Copula function is a uniform distribution. It can be transformed using inverse distribution functions to obtain the correlated sampling of any arbitrary distribution, which in our problem is the Bernoulli distribution. The principle of the correlated sampling is illustrated in Fig. 3, where the dots represent the sampled values of Gaussian Copula.

The distribution of the samples show a positive correlation between two dimensions. Meanwhile, on each dimension the samples $\Phi\left(\tilde{\delta}_{l}\right)$ are uniformly distributed. The states of each segment of lines can be determined by comparing each $\Phi\left(\tilde{\delta}_{l}\right)$ with the corresponding conditional forced outage probability $p_{i, j}$. Such technique guarantees that the outage probability of each segment maintains the preset value while achieving a correlated sampling. For the details of the Copula function, readers can refer to [22].

\section{Framework of mid-short-term risk assessment}

Figure 4 shows the flow chart of the mid-short-term risk assessment that considers the external environment, the 


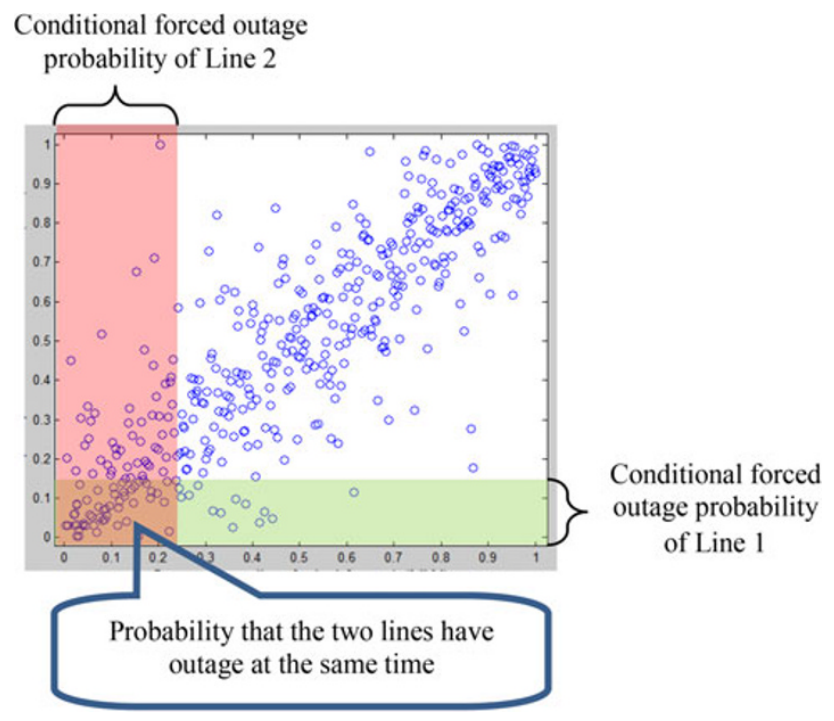

Fig. 3 Principles of the sampling method considering the correlations of multiple lines in the same disaster area

health of the component, load fluctuations, and generating unit outages.

As shown in the flow chart, before sampling the states of transmission lines and transformers the state of the disaster (happen or not) in each area should be sampled. The conditional forced outage probability of each segment in the disaster area is calculated accordingly using the method proposed in Sect. 3.2. If the disaster happens, the correlated sampling technique proposed in Sect. 3.2 should be used, otherwise the ordinary sampling technique that do not consider the correlation should be used. The segments that are not located in any disaster area should also be sampled using the ordinary sampling technique. The state of transmission lines is determined by the logical product of all its segment states since the segments belonging to one transmission line form a series reliability model:

$S_{i}^{\mathrm{E}}=\prod_{j=1}^{k_{i}+1} S_{i, j}$

where $S_{i}^{\mathrm{E}}$ is the state of $i$-th transmission line and $S_{i, j}, j=$ $1,2, \ldots, k_{i}+1$ is the state of each segment.

The sampling technique proposed in this paper only involves the random failure of transmission lines caused by the external environment. Its healthiness dependent failure model is built using the method proposed in [11]. Since the fundamentals of these two kinds of failure are different, the outage occasions can be regarded as independent and the overall state of the transmission line is determined by the logical product of the sampling state of each kind of failure:

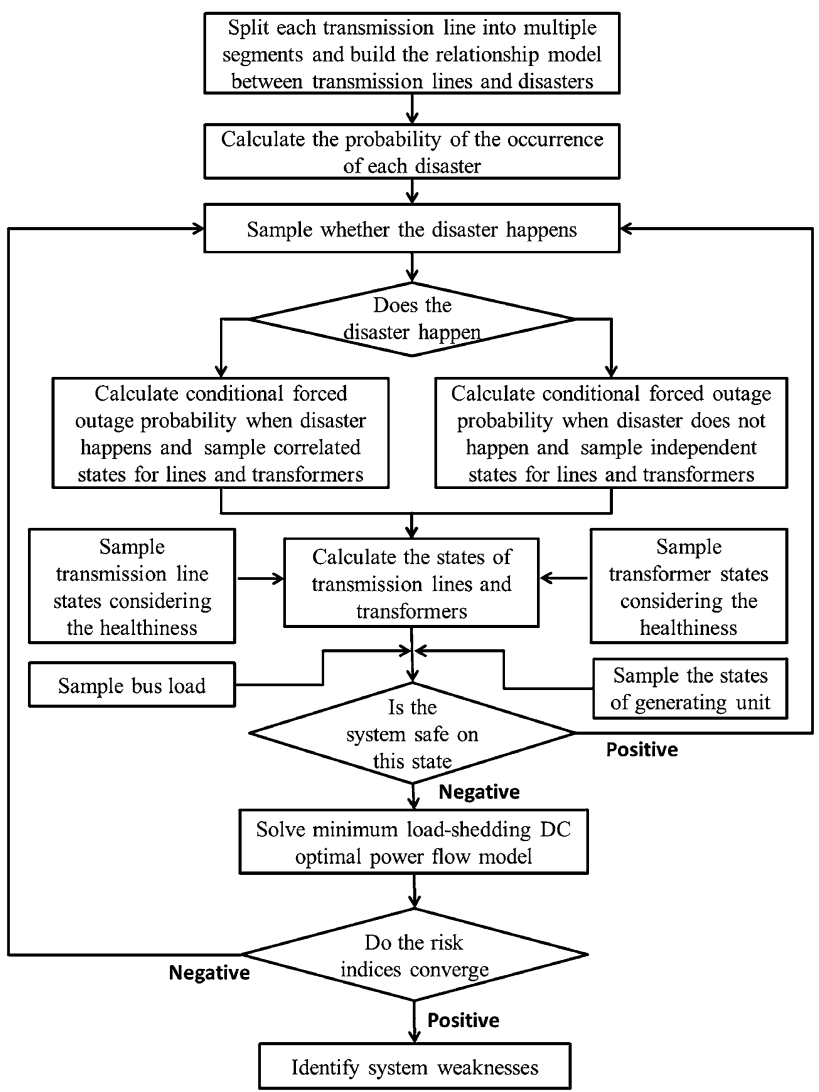

Fig. 4 Flow chart of mid-short-term risk assessment of power system

$S_{i}=S_{i}^{\mathrm{E}} S_{i}^{\mathrm{H}}$,

where $S_{i}$ is the overall state of the $i$-th transmission line, $S_{i}^{\mathrm{E}}$ and $S_{i}^{\mathrm{H}}$ are the sampled states considering the impact of external environment and the healthiness, respectively.

The reliability model of the transformer is very similar with that of transmission lines proposed in Sect. 3. The main difference is that the transformer do not have multiple segments. Its healthiness dependent failure model is built using the model proposed in [23]. The paper will not go into specific on the reliability model of the transformers.

In Fig. 4, the sampling of generating unit and bus load uses ordinary methods proposed in [1]. The sampling of generating units only involves the units that are in operation state or used as standby reserves, while the states of other units are assigned to 0 (stop).

Once the states of all the components are sampled, the system safety under such state is evaluated using DC load flow. If there is overload or electrical island in the power system, the DC optimal load flow model is adopted to calculate the optimal load-shedding on such state. The risk indices are further calculated using the amount of shed load and the convergence of the assessment is evaluated [24]. During the risk assessment, the contribution of each component to system load shedding is calculated using the 
method in [25]. The results can be used to identify the weakness of power systems and can be used as a clue in the decision making of maintenance scheduling and operation planning.

\section{Case study}

\subsection{Basic data}

The real data of Jiangxi provincial power grid was adopted in the case study. A 2-week operational record in 2012 was extracted and used as basic parameters. The system load curve is shown in Fig. 5 with a maximum of $11,820 \mathrm{MW}$. The total capacity of operating and standing by generating units is $15,900 \mathrm{MW}$. The power grid above $220 \mathrm{kV}$ voltage level is considered in the case study.

The distribution of ice storm is considered in the case study, as shown in Fig. 6. The reliability parameters of transmission lines are counted in categories of voltage levels and are listed in Table 2. The table shows that the trip-out rate when the ice storm happens is much higher than that when the ice storm does not happen. The FORs of all the $500 \mathrm{kV} / 220 \mathrm{kV}$ transformers are all set as 0.001725 times/year [26], The FORs of the generating unit are set using the average values of 2009 in China [27], as shown in Table 3.

\subsection{Results}

Six cases are set with different ice storm occurrence probabilities from 0 to 1 with a step of 0.2 . The indices of LOLP and EENS corresponding to all the cases are shown in Fig. 7. The results show that the system has much higher risks while the occurrence probability of the ice storm increases. The LOLP of the case where the disaster has the occurrence probability of 1.0 is more than four times of that when the disaster dose not happen.

We choose 4 lines to demonstrate the impact of the ice storm on the outage probability of lines, namely Wenshan-

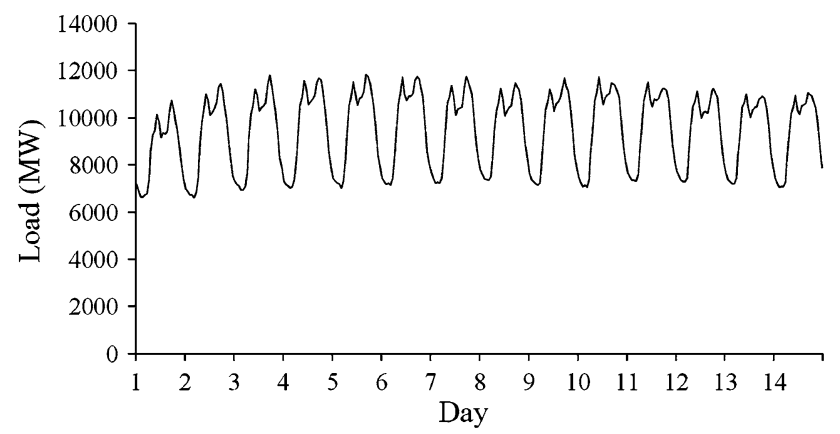

Fig. 5 Load curve of Jiangxi provincial power grid

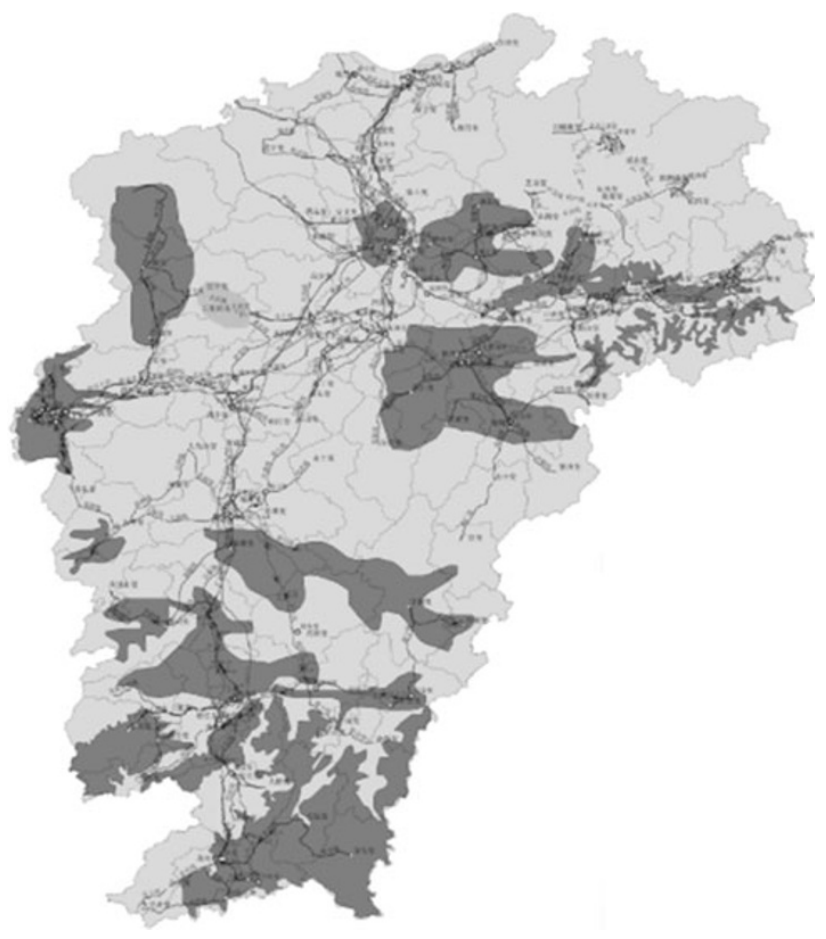

Fig. 6 Ice storm distribution of Jiangxi provincial power grid (dark grey area)

Table 2 Reliability parameters of transmission lines in Jiangxi provincial power grid

\begin{tabular}{lcc}
\hline Index & \multicolumn{2}{c}{ Voltage level } \\
\cline { 2 - 3 } & $220 \mathrm{kV}$ & $500 \mathrm{kV}$ \\
\hline Trip-out rate (times/a/100 km) & 0.8772 & 0.5619 \\
Reclosing success probability (\%) & 52.60 & 57.77 \\
Probability of trip-out caused by ice storm (\%) & 33.75 & 52.50 \\
$\begin{array}{l}\text { Conditional trip-out rate when the ice storm } \\
\text { happens (times/year/100 km) }\end{array}$ & 1.776 & 1.770 \\
$\begin{array}{l}\text { Conditional trip-out rate when the ice storm does } \\
\text { not happen (times/year/100 km) }\end{array}$ & 0.697 & 0.320 \\
\hline
\end{tabular}

Ganzhou I and II, Wan'an-Hugang I and II, respectively. These four lines are the key branches in the south of $\mathrm{Ji}$ angxi provincial power grid and are responsible for supplying the load in Ganzhou area. They are located in a large-scale ice storm area, as shown in Fig. 8. Table 4 lists the sampling results of these four lines in the case which the ice storm occurrence probability is 1 . The total number of sampling times is 600,000 . The results show that the segments of lines located in the ice storm area have much higher outage probability per kilometer than those that do not. These segments increase the overall outage probability of each line. In the sampling, the outage probabilities of these four lines are $0.030745,0.029774,0.022927$, and 0.023217 , respectively. The joint probability that these four 
Table 3 Reliability parameters of generation units

\begin{tabular}{lll}
\hline Unit type & Capacity (MW) & $\begin{array}{l}\text { Forced outage } \\
\text { rate (times/a) }\end{array}$ \\
\hline Thermal unit & 600 MW and above & 1.26 \\
& 300-600 MW & 1.07 \\
Gas turbine unit & - & 1.00 \\
Hydro unit & - & 1.01 \\
\end{tabular}

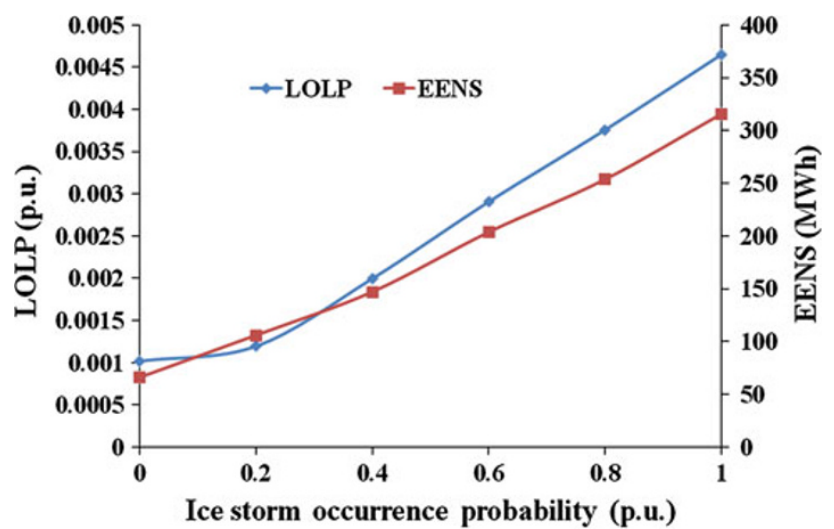

Fig. 7 The impact of the ice storm occurrence probability on the risk level of Jiangxi provincial power grid

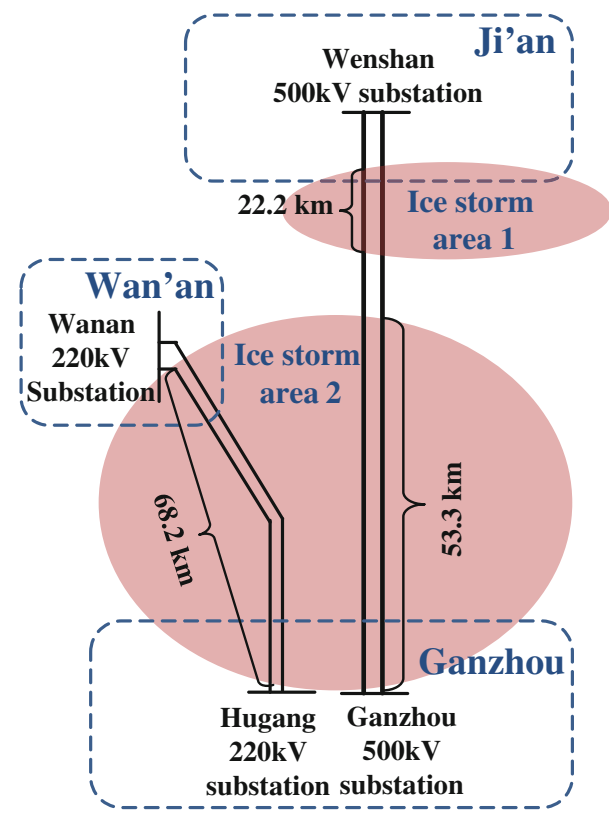

Fig. 8 Relationship between the Wenshan-Ganzhou I \& II, Wan'anShuanghu I \& II and the ice storm disaster

lines having outage together is 0.0053 , which is much higher than the production of the four marginal probabilities. Once the four lines fail together, the Ganzhou area may have load shedding. Simultaneous failure probabilities

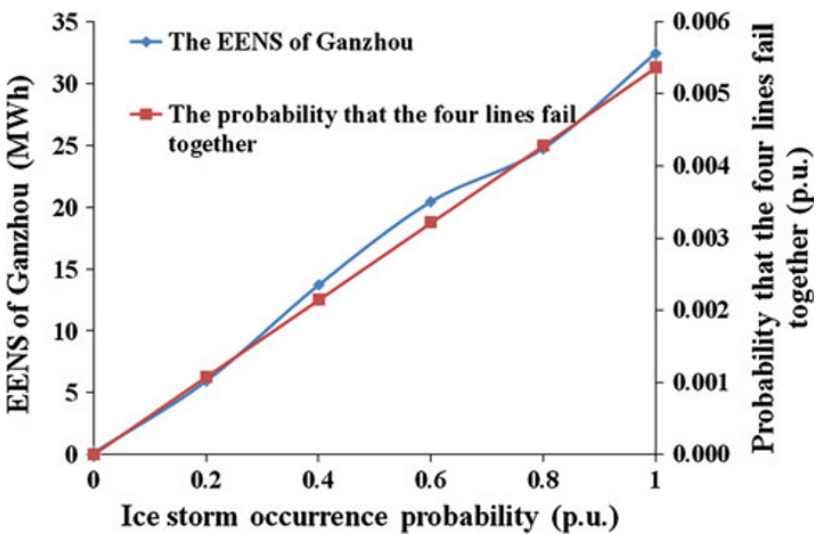

Fig. 9 Impact of the ice storm occurrence probability on the EENS of Ganzhou area and the simultaneous failure probability of lines

of the four lines and the EENSs of Ganzhou in different cases are compared, as shown in Fig. 9. These two indices have a similar trend and partially demonstrate the impact of simultaneous failure of lines on the risk level of Ganzhou area.

The impact of the outage correlation of transmission lines in a same disaster area is analyzed as follows: the correlation coefficient of any two lines in each disaster area is assumed 0.9 (strong correlation), 0.3 (weak correlation) and 0 (dependent), respectively. The ice storm occurrence probability is 0.9 in all three cases. The corresponding system risk indices of the three cases are listed in Table 5. The results show that the LOLP of the strong correlation case is almost the same as other two cases, while the EENS and the economic loss are much higher. The reason is that the outage correlation expands the impacts of the outage and thus causing higher load shedding. The results imply that ignoring the outage correlation of transmission lines in the disaster area would largely underestimate the risk level of the system.

\section{Conclusion}

Disasters such as ice storm, lightning storm and bird migration have significant impact on the power system risk level. A mid-short-term risk assessment model considering external environment is proposed. The impact of natural disasters and the correlation of the multiple component outage occasions are considered in the assessment by modeling the relationship between natural disasters and transmission lines. The techniques of calculating the conditional outage rates and sampling correlated outages in the risk assessment are also proposed. The framework of the mid-short-term risk assessment model is outlined based on the proposed techniques. 
Table 4 Sampling results of each segment of chosen lines when the ice storm happens

\begin{tabular}{|c|c|c|c|c|c|}
\hline Line & Segment & $\begin{array}{l}\text { Length } \\
(\mathrm{km})\end{array}$ & $\begin{array}{l}\text { Failed times in } \\
\text { the sampling }\end{array}$ & $\begin{array}{l}\text { Probability } \\
\text { of outage }\end{array}$ & $\begin{array}{l}\text { Probability of } \\
\text { outage per } \\
\text { kilometer }\end{array}$ \\
\hline \multirow[t]{3}{*}{ Wenshan-Ganzhou I } & 1 & 22.2 & 4,339 & 0.007232 & $3.26 \mathrm{E}-04$ \\
\hline & 2 & 53.3 & 9,582 & 0.01597 & $3.00 \mathrm{E}-04$ \\
\hline & 3 & 77.7 & 4,703 & 0.007839 & $1.01 \mathrm{E}-04$ \\
\hline \multirow[t]{3}{*}{ Wenshan-Ganzhou II } & 1 & 22.2 & 3,840 & 0.006400 & $2.88 \mathrm{E}-04$ \\
\hline & 2 & 53.3 & 9,666 & 0.016109 & $3.02 \mathrm{E}-04$ \\
\hline & 3 & 77.7 & 4,522 & 0.007537 & $9.70 \mathrm{E}-05$ \\
\hline \multirow[t]{2}{*}{ Wanan-Hugang I } & 1 & 68.2 & 13,343 & 0.022239 & $3.26 \mathrm{E}-04$ \\
\hline & 2 & 4.1 & 422 & 0.000704 & $1.72 \mathrm{E}-04$ \\
\hline \multirow[t]{2}{*}{ Wanan-Hugang II } & 1 & 68.2 & 13,501 & 0.022502 & $3.30 \mathrm{E}-04$ \\
\hline & 2 & 4.1 & 439 & 0.000731 & $1.78 \mathrm{E}-04$ \\
\hline
\end{tabular}

Table 5 Impact of the outage correlation of transmission lines in ice storm area on risk level of Jiangxi provincial power grid

\begin{tabular}{llll}
\hline $\begin{array}{l}\text { Correlation coefficient of } \\
\text { any two lines in each ice } \\
\text { storm area }\end{array}$ & $\begin{array}{l}\text { LOLP } \\
\text { (p.u.) }\end{array}$ & $\begin{array}{l}\text { EENS } \\
\text { (MWh) }\end{array}$ & $\begin{array}{l}\text { Economic loss of } \\
\text { load shedding }\left(10^{4}\right. \\
\text { RMB })\end{array}$ \\
\hline 0.9 & 0.004592 & 283.38 & 323.78 \\
0.3 & 0.004572 & 221.58 & 242.67 \\
0 & 0.004582 & 212.19 & 233.27 \\
\hline
\end{tabular}

The case study using the real data of Jiangxi provincial power grid shows that the ice storm multiplies the risk level of the entire system. Furthermore, ignoring the outage correlation of transmission lines in the disaster area would largely underestimate the risk indices. Using the proposed method, the operational weakness of the power system can be identified from both temporal and spatial points of view. The results can further help strengthen the ability of the power system in resisting the large scale blackout by increasing the reserve and redundancy on the weaknesses through the maintenance scheduling and operational planning.

Acknowledgments This work was supported by Jiangxi Electric Power Corporation Key Technical Project (No. 201250601).

Open Access This article is distributed under the terms of the Creative Commons Attribution License which permits any use, distribution, and reproduction in any medium, provided the original author(s) and the source are credited.

\section{References}

[1] Sun YZ, Zhou JQ (2010) Basic theory of online operation reliability of large interconnected power system, doctorial dissertation. Tsinghua University Press, Beijing, China
[2] Billinton R, Singh G (2006) Application of adverse and extreme adverse weather: modelling in transmission and distribution system reliability evaluation. IEE Proc: Gener Transm Distrib 153(1):115-120

[3] Dai Y, Mccalley JD, Abi-samra N (2001) Annual risk assessment for overload security. IEEE Trans Power Syst 16(4):616623

[4] Li BJ, Fang YJ, Xu TS (2013) Review on online operational security risk assessment of power systems. Automot Electric Power Syst 36(4):1-7 (in Chinese)

[5] Pang W, Zhang SN, Li XX (2012) Reflection on a multiple power grid fault caused by inclement weather. Electric Power 45(12):61-65 (in Chinese)

[6] Lin WF, Sun Huadong, Tang Y et al (2010) Analysis and lessons of the blackout in Brazil power grid on November 10, 2009. Autom Electric Power Syst 34(7):1-5 (in Chinese)

[7] Xin K, Wu XC, He SZ (2013) Review on the blackout of power systems and discussion on its security lessons and related countermeasures. South Power Syst Technol 7(1):32-38 (in Chinese)

[8] Xu L (2012) Ice disaster risk evaluation of power system considering multi-factors, doctorial dissertation, South China University of Technology, Guangzhou, China

[9] Ning LY, Wu WC, Zhang BM (2011) Analysis of a time-varying power component outage model for operation risk assessment. Autom Electric Power Syst 33(16):7-12 (in Chinese)

[10] He J, Cheng L, Sun YZ et al (2010) Power system short-term operational reliability evaluation considering weather forecast. Power Syst Prot Control 38(10):31-38 (in Chinese)

[11] He J, Cheng L, Sun YZ et al (2009) Condition dependent shortterm reliability models of transmission equipment. Proc CSEE 29(7):39-46 (in Chinese)

[12] Sun YZ, Wang P, Cheng L et al (2010) Operational reliability assessment of power systems considering condition-dependent failure rate. IET Gener Transm Distrib 4(1):60-72

[13] Xin JB, Wan JB, Hu J et al (2013) Research on the provincial power grid $\mathrm{mid} /$ short term risk assessment system and its uncertainty modeling approach. Power Syst Prot Control 41(1):84-89 (in Chinese)

[14] Xu WJ, Yang HM, Zhao JH et al (2011) Probability calculation of broken transmission lines and collapsed towers under ice storms. Autom Electric Power Syst 35(1):13-17 (in Chinese)

[15] Li WY, Zhou JQ, Xie KG et al (2008) Power system risk assessment using a hybrid method of fuzzy set and Monte Carlo simulation. IEEE Trans Power Syst 3(2):336-343 
[16] Feng YQ, Wu WC, Zhang BM et al (2008) Power system operation risk assessment using credibility theory. IEEE Trans Power Syst 23(3):1309-1318

[17] Liu Y, Singh C (2011) A methodology for evaluation of hurricane impact on composite power system reliability. IEEE Trans Power Syst 26(1):145-152

[18] Song XZ, Wang Zhen, Gan DQ et al (2012) Transient stability risk assessment of power grid under typhoon weather. Power Syst Prot Control 40(24):1-8 (in Chinese)

[19] Cheng L, He J, Sun YZ (2012) Impact of transmission line's real-time reliability model parameter upon power system operational reliability evaluation. Power Syst Technol 30(13):8-13 (in Chinese)

[20] Brostrom E (2007) Ice strom modelling in transmission system reliability calculations. Doctorial Dissertation, Royal Institute of Technology, Stockholm, Sweden

[21] Morales JM, Mínguez R, Conejo AJ (2010) A methodology to generate statistically dependent wind speed scenarios. Appl Energy 87(3):843-855

[22] Nelsen RB (1998) An introduction to copulas. Springer, New York

[23] Ning LY, Wu WC, Zhang BM (2011) Time-varying transformer outage model for operational risk assessment, Part one: condition based failure rate estimation method for transformer internal latent fault estimation. Autom Electric Power Syst 34(15):9-13 (in Chinese)

[24] Li W (2005) Risk assessment of power systems: models, methods, and applications. IEEE Press/Wiley, USA/Canada

[25] $\mathrm{Hu} \mathrm{B}$, Xie KG, Li XL et al (2005) Techniques of tracing the unreliability contributions of HVDC transmission system components. Proc CSEE 30(10):29-35 (in Chinese)

[26] Wang MY (2007) Statistic analysis of transformer's faults and defects at voltage $110 \mathrm{kV}$ and above. Distr Util 24(1):1-5

[27] Generating unit operation reliability indices of thermal, hydro and nuclear power plant, China (2009). http://wenku.baidu.com/ view/61891cabd1f34693daef3e6d. Accessed 1 Jul 2013

\section{Author Biographies}

Ning ZHANG is a post-doctor in Tsinghua University. He is an IEEE member and his research interests include power system planning, power system risk assessment, renewable energy and power system operation.

Chongqing KANG is a professor of Tsinghua University. He is an IET Fellow and an IEEE senior member, his research interests include low-carbon electricity, power system planning, power markets and power system load forecasting.

Jingkun LIU is Ph.D. student of Tsinghua University. He is an IEEE student member, and his research interest is power system risk analysis.

Jianbo XIN is the chief engineer of Jiangxi Electric Power Research Institute. His research areas include power system operation and control, intelligent substations and distributed power system technology.

Junbiao WAN is a senior engineer of Jiangxi Electric Power Research Institute. His working area is transmission facility condition monitoring.

Jing HU is an engineer of Jiangxi Electric Power Research Institute. His working area is transmission facility condition monitoring.

Wenxiao WEI is a master student in Harbin Institute of Technology. Her research interests include power system analysis and control, distribution network optimization. 